\title{
NEONATAL CAPSAICIN AND GUANETHIDINE AND AXONALLY TRANSPORTED ORGANELLE-SPECIFIC ENZYMES IN SCIATIC NERVE AND IN SYMPATHETIC AND DORSAL ROOT GANGLIA ${ }^{1}$
}

\author{
D. B. McDOUGAL, JR., ${ }^{2}$ M. J. C. YUAN, R. V. DARGAR, AND E. M. JOHNSON, JR. \\ Washington University School of Medicine, Department of Pharmacology, St. Louis, Missouri 63310
}

Received January 29, 1982; Revised August 3, 1982; Accepted August 3, 1982

\begin{abstract}
The sciatic nerves of rats were "dissected" by neonatal deletion of different types of neurons using relatively specific neurotoxins. The amounts of various enzyme activities in transit in different axonal types can be inferred by comparison of treated and control nerves.

Accumulations by axoplasmic transport of selected enzyme activities proximal and distal to a tie placed on the sciatic nerve were monitored in adult rats exposed on the 2nd postnatal day to capsaicin $(50 \mathrm{mg} / \mathrm{kg})$ and/or to guanethidine $(50 \mathrm{mg} / \mathrm{kg}$ daily, 5 days per week, from the 7 th to the 28th postnatal day). Littermates were treated with the two vehicles. Proximal and distal accumulations of $\mathrm{F}^{-}$-inhibitable acid phosphatase activity were reduced about $55 \%$ in animals pretreated with capsaicin and 10 to $20 \%$ in animals pretreated with guanethidine. The $\mathrm{F}^{-}$-inhibitable acid phosphatase activity has been found to be the product of at least two different enzyme activities, one of which is relatively sensitive to $\mathrm{L}-(+)$-tartrate inhibition, probably the lysosomal enzyme, and one rather resistant to tartrate inhibition. Accumulation of the tartrate-sensitive activity was reduced about $40 \%$ in the nerves of capsaicin-treated animals but was unaffected by guanethidine pretreatment. Accumulation of the tartrate-resistant activity was reduced about $70 \%$ in nerves of capsaicin-treated animals but was not significantly reduced in guanethidine-treated animals. Accumulation of acetylcholinesterase activity was reduced $35 \%$ by guanethidine pretreatment but was unaffected by capsaicin. Accumulations of the mitochondrial enzyme activities, glutaminase, hexokinase, and glutamic dehydrogenase, were reduced about $1 / 3$ each by capsaicin and guanethidine pretreatment. The mitochondrial results were most clear-cut with glutaminase, which appeared to be relatively more active in axonal than in Schwann cell mitochondria. Transport of ${ }^{125}$ I-labeled nerve growth factor from the forepaw to the cervical dorsal root ganglia was reduced about $15 \%$ by capsaicin treatment. The concentrations of $\mathrm{F}^{-}$-inhibitable acid phosphatase, $\beta$-glucuronidase, and glutaminase activities were reduced 20 to $30 \%$ in lumbar dorsal root ganglia of capsaicin-treated animals. Tartrate-sensitive acid phosphatase activity was reduced only 13\%, while the tartrateresistant activity fell 53\%. Hexokinase and glutamic dehydrogenase activities were unchanged. Guanethidine had no effect upon enzyme activities measured in dorsal root ganglia. Tyrosine hydroxylase, acetylcholinesterase, glutaminase, and $\mathrm{F}^{-}$-inhibitable acid phosphatase activities were reduced 86 to $98 \%$ in superior cervical ganglia from guanethidine-treated rats but were unaffected by capsaicin treatment.

The results were interpreted to suggest that tartrate-inhibitable acid phosphatase activity, and perhaps lysosomes, are concentrated in the axons of the neurons which are susceptible to nconatal capsaicin, perhaps in response to a need for repeated repair of the peripheral terminals of these axons, whose function exposes them to increased risk of injury. Furthermore, unmyelinated axons, both sensory and sympathetic, appear to transport disproportionately large amounts of mitochondria, which may be a consequence of their high surface-to-volume ratio.

In fixed tissue sections, there is an acid phosphatase activity found in the capsaicin-sensitive neurons of the dorsal root ganglia and in their terminals in the substantia gelatinosa. It seems likely that the tartrate-resistant acid phosphatase activity will prove to be this activity.
\end{abstract}

\footnotetext{
'This work was supported by National Institutes of Health Grants NS 11941 and HL 20604. E. M. J. is an Established Investigator of the American Heart Association. We thank Dr. Pamela Toy-Manning for assistance with some of the dissections and for one of the assays, Ms. Anne Dillon for the illustrations, and Ms. Linda Hammond and
}

Jacquelyn Udell for typing the mansucript.

${ }^{2}$ To whom correspondence should be addressed at Washington University School of Medicine, Department of Pharmacology, 660 South Euclid Avenue, St. Louis, MO 63110. 
The mitochondria, lysosomes, and other membranous bodies in motion in peripheral nerve travel in a variety of different kinds of axons, sensory, sympathetic, and motor. By using treatments which destroy neurons, and therefore their axons, with some specificity, this anatomical complexity can be reduced. A comparison of various organelle-specific enzymes in motion (i.e., accumulating at a tie) in control nerves and in nerves subjected to specific neuronal depletion allows one to assign measured fractions of the moving substances to the appropriate neurons, either those surviving or those deleted. By removing sympathetic axons and neurons specifically with neonatal guanethidine treatment (Johnson et al., 1975,1976 ) and by removing sympathetic plus most of the sensory axons and neurons with prenatal nerve growth factor (NGF) deprivation (Gorin and Johnson, 1979), it has been shown that the organelles in motion differ from one type of axon to another (Schmidt et al., 1978; McDougal et al., 1981). Specifically, in the study of the effects of prenatal nerve growth factor deprivation upon enzyme activities in motion in sciatic nerve, the close correlation found between the fraction of sensory neurons lost (69\%) and the loss of fluoride-sensitive acid phosphatase (FSAP) activity (75\%) in motion in the sciatic nerve implied that most of the FSAP activity in motion in the nerve was travelling in the sensory axons (McDougal et al., 1981).

The discovery that capsaicin damages primarily the small sensory neurons of the dorsal root ganglia (Jancsó et al., 1977), thereby interfering with chemogenic nociception, provides still another neuroloxin with which to "dissect" peripheral nerve. The fact that not all sensory neurons are affected by the poisin enables a more detailed examination of the association of FSAP with sensory axons. In the present study neonatal capsaicin treatment was used to remove small sensory neurons and their (unmyelinated) axons (Jancsó et al., 1977), and neonatal guanethidine treatment was used to produce permanent sympathectomy.

A nonlysosomal acid phosphatase activity is known from slide histochemical studies to be associated with the capsaicin-sensitive neurons (Jancsó and Knyihár, 1975; Jessell et al., 1978). This enzyme is more resistant to fluoride inhibition than is the lysosomal activity (Gerebtzoff and Maeda, 1968). We have devised a quantitative assay for this enzyme using tartrate instead of fluoride inhibition as explained below. We have used the assay to characterize the partitioning of FSAP activity between what we take to be its lysosomal and nonlysosomal forms.

In addition, evidence is presented that capsaicin-sensitive sensory neurons can transport NGF, that capsaicin has no lasting deleterious effect upon sympathetic neurons, and that both the small, unmyelinated axons of capsaicin-sensitive neurons and those of postganglionic sympathetic neurons are rich in transported mitochondria.

\section{Materials and Methods}

Pregnant Sprague-Dawley rats were obtained from Zivic-Miller Laboratories, Inc. The day after birth, onehalf of the pups in each litter was given one injection (subcutaneous) of capsaicin, $50 \mathrm{mg} / \mathrm{kg}$, prepared in ethanol/Tween $80 /$ saline at $10 \mathrm{mg} / \mathrm{ml}$ (Jancsó et al.,
1977); the other half was given vehicle alone $(5 \mu \mathrm{l} / \mathrm{gm})$. Starting when the animals were 7 days old, one-half of the capsaicin-injected animals and one-half of the vehicle-injected animals were injected with guanethidine, 50 $\mathrm{mg} / \mathrm{kg}(10 \mu \mathrm{l} / \mathrm{gm}$ of a solution containing $5 \mathrm{mg} / \mathrm{ml}$, s.c.). The remaining animals received $10 \mu \mathrm{l} / \mathrm{gm}$ of $0.15 \mathrm{M} \mathrm{NaCl}$. These injections were given once each day, 5 days each week for 3 weeks (Johnson et al., 1976). Thus, each litter was divided into four groups: control (treated with both vehicles), capsaicin alone (also treated with guanethidine vehicle), guanethidine alone (also treated with capsaicin vehicle), and a fourth group treated with both capsaicin and guanethidine.

When the animals were 5 months old, the sciatic nerves were tied in midthigh under pentobarbital anesthesia (Schmidt and McDougal, 1978). A second group of animals was treated in an identical fashion but was $2^{1 / 2}$ months old at the time of sciatic ligation. The nerves were left in vivo for $24 \mathrm{hr}$, then the animals were killed, and the nerves, lumbar dorsal root ganglia, and superior sympathetic ganglia were removed, frozen on solid $\mathrm{CO}_{2}$, and lyophilized at $-40^{\circ} \mathrm{C}$. The nerves were cut into pieces $2 \mathrm{~mm}$ long, desheathed, and weighed as described previously (McDougal et al., 1981). The dorsal root ganglia were desheathed and the attendant roots and nerves were cut as short as possible. The superior cervical ganglia were stripped of adventitious tissue and the nerves were cut off, but the dried ganglia could not be cleanly desheathed. The tissues were homogenized in $0.1 \mathrm{~m}$ phosphate buffer, $\mathrm{pH} 7.4$, with added bovine serum albumin, $0.05 \%$. The homogenates were quick-frozen in acetone chilled with solid $\mathrm{CO}_{2}$ and kept at $-70^{\circ} \mathrm{C}$ between assays. These homogenates were used without further processing for all the assays.

Activities of $\mathrm{F}^{-}$-sensitive ( $\mathrm{F}^{-}$-inhibitable) acid phosphate (FSAP; orthophosphoric monoester phosphohydrolase, EC 3.1.3.1.), acetylcholinesterase (AChE; acetylcholine hydrolase, EC 3.1.1.7), glutaminase (L-glutamine amino hydrolase, EC 3.5.1.2), hexokinase (ATP:D-hexose 6-phosphotransferase, EC 2.7.1.1), and glutamic dehydrogenase (L-glutamate:nicotinamide adenine dinucleotide oxidoreductase (deaminating), EC 1.4.1.2) were assayed by methods listed or described by McDougal et al. (1981). $\beta$-Glucuronidase $(\beta$-D-glucuronide glycuronohydrolase, EC 3.2.1.31) was assayed, following the method of Robins et al. (1968), in sodium acetate buffer, $80 \mathrm{~mm}, \mathrm{pH} 3.75$, using 4-methylumbelliferyl $\beta$-D-glucuronide, $1 \mathrm{~mm}$, as substrate in the presence of $0.05 \%$ bovine serum albumin. Tyrosine hydroxylase was measured in a separate group of ganglia by a minor modification of the method of Nagatsu et al. (1964) as described by Gorin and Johnson (1979). None of the assays was adversely affected by lyophilization. Results of the enzyme assays are expressed in millimoles of product produced per $\mathrm{kg}$ dry weight of nerve or ganglion per hour, or in units per nerve or ganglion, where 1 unit equals $1 \mathrm{nmol}$ of product produced per hr.

Analytical fractionation of FSAP. In fixed sections the fluoride-sensitive acid phosphatase can be separated histochemically by the use of low levels of fluoride into a more sensitive form, seen in the lysosomes, and a less sensitive form, which is extralysosomal (Gerebtzoff and Maeda, 1968). However, the kinetics of fluoride inhibition 
are far from straightforward (Reiner et al., 1955). It was found simpler to work out the quantitative assay using $\mathrm{L}-(+)$-tartrate, another good inhibitor of the lysosomal acid phosphatase: the basic reagent consisted of $10 \mathrm{~mm}$ $\alpha$-naphthyl phosphate in $50 \mathrm{~mm}$ Tris-succinate buffer, $\mathrm{pH} 5.1$, containing $0.05 \%$ bovine serum albumin and $0.025 \%$ Triton $\mathrm{X}-100$. This reagent was used (1) without further additions (2) with $0.9 \mathrm{~mm} \mathrm{~L}-(+)$-tartrate, and (3) with $10 \mathrm{~mm} \mathrm{KF}$. A portion of the sample (10 to $20 \mu \mathrm{g}$ dry weight) was incubated in 75 to $100 \mu \mathrm{l}$ of each of the three reagents for 30 to $60 \mathrm{~min}$ at $38^{\circ} \mathrm{C}$. The reaction was stopped with $1 \mathrm{ml}$ of $0.1 \mathrm{~N} \mathrm{NaOH}$ and the resulting fluorescence was measured. The activity in the reagent lacking inhibitors (1) minus that in the tartrate-containing reagent (2) gave the tartrate-sensitive acid phosphatase (TSAP) activity. The activity in the tartrate-containing reagent (2) minus that in the fluoride-containing reagent (3) gave the tartrate-resistant acid phosphatase (TRAP) activity, which appears to correspond to the enzyme labeled "fluoride-resistant" by others (Knyihár and Gerebtzoff, 1973; Jessell et al., 1978; Nagy and Hunt, 1982). Although TRAP has not yet been purified, experiments using crude tissue homogenates suggest that the $K_{\mathrm{i}}$ for tartrate for the two activities differ by a factor of 40 to 50 , allowing adequate separation of the two activities by the concentrations of substrate and tartrate used.

Neither the assay with $p$-nitrophenyl phosphate (McDougal et al., 1981) nor that with $\alpha$-naphthyl phosphate has been designed for optimal fluoride-resistant activity. Therefore, the fluoride-resistant acid phosphatase activities will not be reported. However, the fluorideresistant acid phosphatase activity of the rat nervous system is largely due to low molecular weight enzymes (D. B. McDougal, Jr., R. V. Dargar, and M. J. C. Yuan, manuscript in preparation), like one found in bovine brain (Chaimovich and Nome, 1970). These enzymes have very low activity with $\alpha$-naphthyl phosphate, so that the total acid phosphatase activity seen using this substrate is almost entirely FSAP; that is, it is essentially completely inhibited by 3 to $10 \mathrm{~mm} \mathrm{~F}^{-}$. For examplc, using $p$-nitrophenyl phosphate, $28 \%$ of the acid phosphatase activity accumulated at a 1-day tie on sciatic nerve and $43 \%$ of the activity in dorsal root ganglia is fluoride resistant. Using $\alpha$-naphthyl phosphate, these numbers are only $5 \%$ and $4 \%$, respectively.

Two other groups of animals, treated only with capsaicin or vehicle (no guanethidine), were used. In one group, retrograde transport of ${ }^{125}$ I-labeled nerve growth factor $\left({ }^{125} \mathrm{I}-\mathrm{NGF}\right)$ from the forepaw to the cervical dorsal root ganglia C5 to C8 (Gorin and Johnson, 1979) was examined. Lumbar dorsal root ganglia $\left(\mathrm{L}_{3}\right.$ to $\left.\mathrm{L}_{5}\right)$ were taken from the other group for the assay of TSAP and TRAP activities.

Enzyme accumulations at the tie were calculated as described previously (Schmidt and McDougal, 1978; Schmidt et al., 1980). Significance of differences was assessed using the Student's $t$ test.

\section{Results}

Animals treated neonatally with capsaicin consistently fail to respond with writhing to intraperitoneal $5 \%$ acetic acid or with blepharospasm and scratching at the eye to intraocular instillation of dilute capsaicin $(0.01$ to $0.1 \mathrm{mg} /$ $\mathrm{ml}$ in $0.15 \mathrm{M} \mathrm{NaCl}$ ). They appear to be normally responsive to cold, as judged by the rapidity with which they step off a plastic-covered block of solid $\mathrm{CO}_{2}$, and to pin prick, as judged by their vocalization and struggling when injected, for example, for anesthesia.

\section{Control nerves}

The enzyme activities studied varied greatly in the accumulations produced at a tie left on the sciatic nerve for $24 \mathrm{hr}$ relative to the activity of the enzyme present in undisturbed nerve (intrinsic activity) (Fig. 1). For example, in control nerves accumulated FSAP activity was more than 12 times the intrinsic activity. Less than $20 \%$ of the accumulated activity was inhibitable by $0.9 \mathrm{~mm}$ tartrate (TSAP). Even so, it was found that accumulation of TSAP activity, presumed to be the lysosomal form of the enzyme, was still 4 times the intrinsic activity proximal to the ligature and almost 7 times the intrinsic activity distally. It is noteworthy that the proximal accumulation was only $60 \%$ as large as the distal, suggesting, perhaps, that this enzyme activity turns around at the tie more rapidly than do the other enzymes studied (Schmidt et al., 1980). $\beta$-Glucuronidase activity, which is also lysosomal, accumulated to only $2^{1 / 2}$ times the intrinsic activity. Similarly, for the mitochondrial enzymes studied, glutaminase activity accumulated more with respect to intrinsic activity than did either hexokinase or glutamic dehydrogenase activity, suggesting that peripheral neurons have relatively more glutaminase activity and Schwann cells more glutamic dehydrogenase activity, as has been found for relatively pure preparations of central neurons and glia, respectively, by Patel et al. (1981). AChE activity accumulated to 10 times the intrinsic activity. TRAP activity is another enzyme which may be associated with synaptic function (Csillik and Knyihár, 1978). Its accumulation, which accounted for more than $80 \%$ of FSAP accumulation, was the highest we have seen in terms of intrinsic activity, 25 times, both proximal and distal to the ligature. Although it is clear that FSAP activity is a composite of TSAP and TRAP, we will report the changes in FSAP activity as well as those in TSAP and TRAP activities in this paper to enable comparison with our earlier results (Schmidt et al., 1978, 1980; McDougal et al., 1981).

Since the deletion of axons from nerve is likely to result in either no change or a decrease in transported enzyme activity, not in an increase, changes in the enzymes accumulating in large amounts above the intrinsic activity are most likely to be seen consistently.

\section{Experimental nerves}

Proximal and distal accumulations of FSAP activity at the tie on nerves from animals treated as neonates with capsaicin were much less than those in nerves from control animals (Fig. 2). A similar difference was seen between the accumulations in nerves from animals pretreated with both capsaicin and guanethidine and those in nerves from animals treated only with guanethidine. In two of the four possible comparisons (control vs. guanethidine treated, capsaicin treatment vs. combined treatment; proximal and distal), guanethidine also ap- 


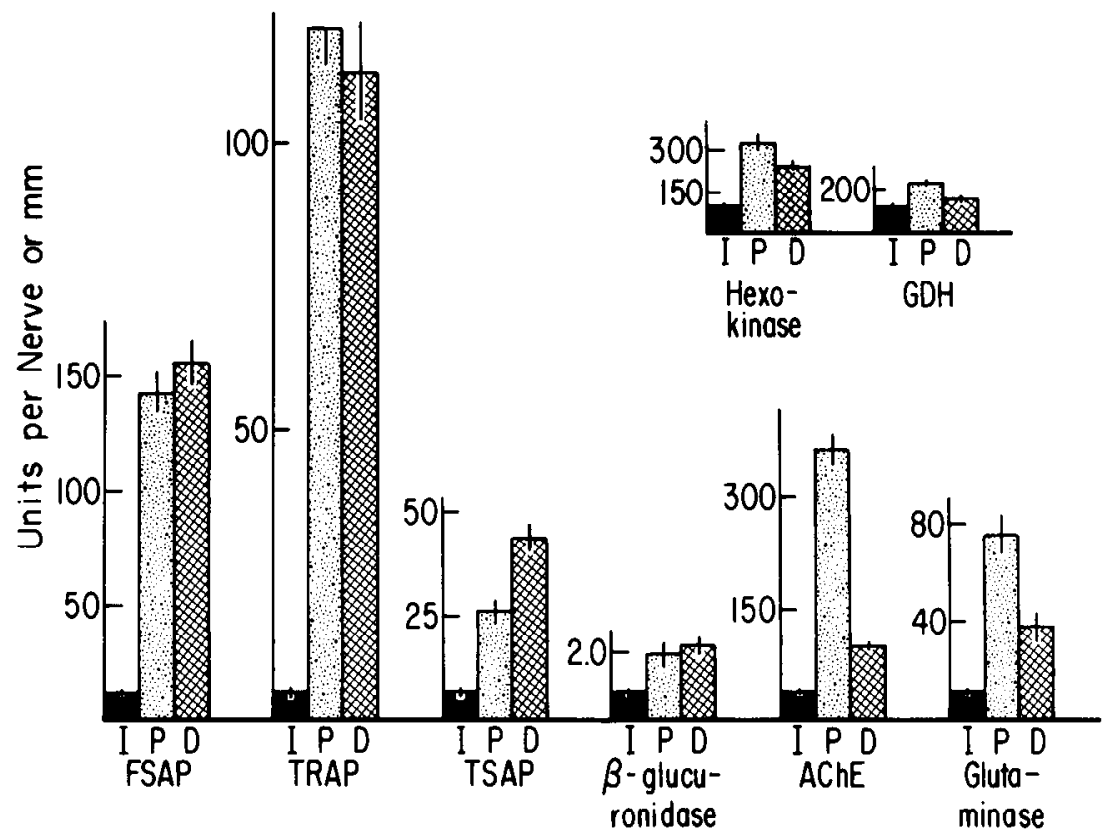

Figure 1. Intrinsic activities $(I)$, in units per millimeter, and proximal $(P)$ and distal $(D)$ 24-hr accumulations of activities, in units per nerve, for eight enzyme activities in control nerves. Six activities in seven nerves were measured in 5-month-old animals. Two activities, TSAP and TRAP, were measured in six nerves from $2 \frac{1}{2}$-month-old animals. Note that the ordinate has been adjusted for each enzyme so that the bars indicating the intrinsic activities are the same height for all eight enzymes. $G D H$, glutamic dehydrogenase. The means \pm SEM are indicated.

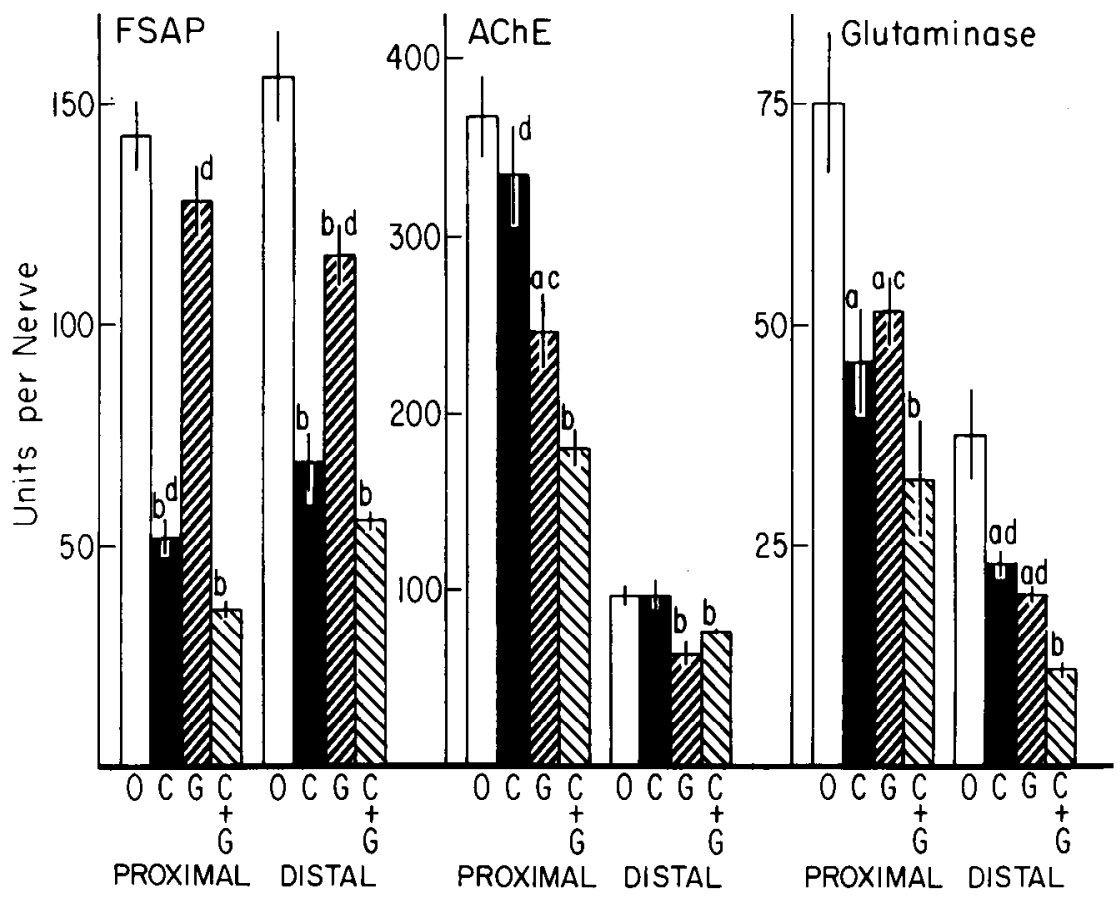

Figure 2. Accumulations of FSAP, AChE, and glutaminase activities proximal and distal to a ligature placed on the sciatic nerve and left in vivo for $24 \mathrm{hr}$ in control animals $(O)$ and in animals treated with capsaicin $(C)$, guanethidine $(G)$, and both substances $(C+G)$. Five-month-old animals and four to eight nerves are presented. The SEM is indicated. $a$, Different from control, $p \leq 0.05 ; b$, different from control, $p \leq 0.01 ; c$, different from combined treatment group, $p \leq 0.05 ; d$, different from combined treatment group, $p \leq 0.01$.

peared to produce a decrease, though the effect was much less. Combining the data, somewhat more than $50 \%$ of the FSAP activity in motion could be assigned to capsaicin-sensitive axons. Perhaps 10 to $15 \%$ travels in sympathetic axons.
In a second group of animals ( $2 \frac{1}{2}$ months old), the accumulations of FSAP activity were somewhat smaller. Nevertheless, the pattern of changes was similar to the first (Table I). The changes produced by guanethidine were small but were statistically significant in three of 
TABLE I

Accumulation of fluoride-sensitive acid phosphatase activity in sciatic nerve: Effects of capsaicin and guanethidine

The differences due to capsaicin (Caps) treatment on lines 2 and 4 were obtained by subtracting the accumulation in group 2 from that in group 1 and the accumulation in group 4 from that in group 3, respectively. Similarly, the differences due to guanethidine (Guan) treatment on lines 3 and 4 were obtained by subtracting the accumulation in group 3 from that in group 1 and the accumulation in group 4 from that in group 2 , respectively. $\mathrm{N}$ is the number of nerves in each group; $2^{1 / 2} 2$-month-old animals were used. The data are expressed as mean $\pm \mathrm{SEM}$ for the proximal and distal accumulations; the differences due to capsaicin and/or guanethidine are given \pm SED.

\begin{tabular}{|c|c|c|c|c|c|c|c|c|c|}
\hline & \multirow{3}{*}{$\mathbf{N}$} & \multicolumn{4}{|c|}{ Proximal } & \multicolumn{4}{|c|}{ Distal } \\
\hline & & \multirow[b]{2}{*}{ Accumulation } & \multicolumn{3}{|c|}{ Difference due to } & \multirow[b]{2}{*}{ Accumulation } & \multicolumn{3}{|c|}{ Difference due to } \\
\hline & & & Caps & Guan & $\begin{array}{c}\text { Caps + } \\
\text { Guan }\end{array}$ & & Caps & Guan & $\begin{array}{c}\text { Caps + } \\
\text { Guan }\end{array}$ \\
\hline & & \multicolumn{8}{|c|}{ units per nerve } \\
\hline 1. Control & 12 & $100 \pm 5$ & & & & $109 \pm 6$ & & & \\
\hline 2. Capsaicin & 8 & $44 \pm 3^{a, b}$ & $56 \pm 6$ & & & $46 \pm 3^{a}$ & $63 \pm 7$ & & \\
\hline
\end{tabular}

${ }^{a} p \leq 0.01$ vs. control.

${ }^{b} p \leq 0.01$ vs. combined treatment groups.

${ }^{c} p \leq 0.05$ vs. control.

four comparisons. The changes produced by capsaicin were large and consistent. The proportions of enzyme activity in motion to be assigned to the two classes of axons are the same as in the first experiment. In both experiments, the FSAP activity accumulating proximal to the tie was reduced $75 \%$ and the distal accumulation was reduced nearly $65 \%$ by the combined treatment regimen.

One-half of the nerves in the second group were reassayed using tartrate to separate the two fluoride-sensitive acid phosphatase activities (Table II). Both proximal and distal accumulations of the presumed lysosomal enzyme activity, TSAP, were significantly reduced (34 to $45 \%$ ) in nerves from capsaicin-treated animals, and the distal accumulation was reduced in the nerves of animals exposed to the combined treatment. Guanethidine did not appear to have any effect on the accumulation of this enzyme. The reductions in both proximal and distal accumulations of TRAP activity were considerably greater (66 to 80\%) in both groups of animals exposed to capsaicin. Although the accumulation of this enzyme appeared to be lower in the two groups of guanethidinetreated animals, the effect was much less and was not statistically significant. Combined with the results of the FSAP assay, however, the data suggest that there may be some TRAP activity moving in sympathetic axons.

The situation with respect to AChE activity was quite different (Fig. 2). Here, guanethidine treatment alone produced a significant decrease in both proximal and distal accumulations. Combined treatment with capsaicin and guanethidine depressed proximal accumulation of the enzyme to a greater extent than guanethidine alone. Capsaicin alone had no statistically significant effect on accumulation of the enzyme. Hence, it appears that 30 to $40 \%$ of the AChE activity travels in sympathetic axons, while little or none travels in the axons of capsaicin-sensitive neurons.

Each neurotoxin produced significant decreases in the accumulations of glutaminase activity (Fig. 2). Their effects were approximately additive. From the combined data it appears that roughly one-third of the enzyme
TABLE II

Accumulation of the tartrate-sensitive and tartrate-resistant acid phosphatase activities at a tie on sciatic nerve

\begin{tabular}{|c|c|c|c|c|}
\hline & \multicolumn{2}{|c|}{ Tartrate Sensitive } & \multicolumn{2}{|c|}{ Tartrate Resistant } \\
\hline & Proximal & Distal & Proximal & Distal \\
\hline & \multicolumn{4}{|c|}{ units per nerve } \\
\hline Control $(6)^{a}$ & $25.8 \pm 3.1$ & $43.5 \pm 3.4$ & $120.0 \pm 6.1$ & $112.4 \pm 8.7$ \\
\hline Capsaicin (4) & $14.0 \pm 1.4^{b}$ & $28.9 \pm 5.0^{c}$ & $40.8 \pm 1.9^{b}$ & $37.5 \pm 4.8^{b}$ \\
\hline $\begin{array}{l}\text { Guanethidine } \\
\text { (4) }\end{array}$ & $22.7 \pm 4.2$ & $45.2 \pm 3.8^{d}$ & $97.3 \pm 8.0^{d}$ & $92.4 \pm 7.3^{d}$ \\
\hline $\begin{array}{l}\text { Capsaicin + } \\
\text { guanethi- } \\
\text { dine (4) }\end{array}$ & $15.7 \pm 4.0$ & $24.8 \pm 3.8^{b}$ & $30.4 \pm 8.0^{b}$ & $22.8 \pm 4.8^{b}$ \\
\hline
\end{tabular}

"The number of nerves is given in parentheses; the same animals as in Table I were used.

${ }^{b} p \leq 0.01$ vs. control.

${ }^{c} p \leq 0.05$ vs. control.

${ }^{d} p \leq 0.01$ vs. combined treatment group.

activity in motion travels in capsaicin-sensitive axons and another third travels in sympathetic axons.

The data for the other mitochondrial enzyme activities, hexokinase and glutamic dehydrogenase (Table III), support the same conclusions-that roughly one-third of mitochondria in motion travel in each of the two toxinsensitive classes of axons and that the effects of the two toxins are additive, so that in the combined treatment groups only one-third of the proximal and distal accumulations remains.

The data for $\beta$-glucuronidase accumulation were quite unsatisfactory (not shown), perhaps partly because the accumulation of this enzyme is small compared to the intrinsic activity (Fig. 1). It appeared that accumulation of the enzyme activity was depressed by capsaicin, but in only one instance was the difference statistically significant.

Neither capsaicin nor guanethidine produced a consistent, statistically significant decrease in the intrinsic activities of any of the enzyme activities measured or in the dry weight of the nerves (not shown). The data 
suggest that not more than $10 \%$ of the dry weight of the nerve could have been deleted by either agent.

Dorsal root ganglia. The effects of neonatal capsaicin and guanethidine treatment on the enzymes of the sensory spinal ganglia were in keeping with their effects on axonally transported enzymes. Both FSAP and $\beta$-glucuronidase were depressed approximately $30 \%$ by capsaicin and, as expected, were unaffected by guanethidine (Table IV). Unlike the situation in nerve, the FSAP activity in control ganglia was partitioned approximately equally between TSAP and TRAP (Table V). With capsaicin treatment, however, TSAP activity was reduced only $13 \%$, while TRAP activity was reduced $53 \%$. In this experiment, the combined activities (FSAP) fell $34 \%$, comparable to the reduction seen in Table IV. There was no measurable decrease in ganglionic dry weight in the capsaicin-treated animals. Of the mitochondrial enzymes only glutaminase showed a consistent significant decrease, 22 to $26 \%$, with capsaicin treatment (Table IV). Capsaicin appeared to depress hexokinase activity in the combined treatment groups as compared to the group treated with guanethidine alone. The increase in hexokinase activity in the guanethidine-treated group as compared to the control group is small but statistically significant. Its meaning is unknown.

TABLE III

Selected enzyme activities accumulating at a tie on sciatic nerve: Effects of capsaicin and guanethidine

\begin{tabular}{|c|c|c|c|c|}
\hline & \multicolumn{2}{|c|}{ Hexokinase } & \multicolumn{2}{|c|}{ Glutamic Dehydrogenase } \\
\hline & Proximal & Distal & Proximal & Distal \\
\hline & \multicolumn{4}{|c|}{ units per nerve $e^{a}$} \\
\hline Control $(7)^{b}$ & $329 \pm 31$ & $242 \pm 11$ & $225 \pm 13$ & $158 \pm 12$ \\
\hline $\begin{array}{l}\text { Capsaicin (5- } \\
\text { 6) }\end{array}$ & $244 \pm 9^{c_{+} d}$ & $191 \pm 11^{d, e}$ & $160 \pm 15^{d, e}$ & $100 \pm 8^{d, e}$ \\
\hline $\begin{array}{l}\text { Guanethidine } \\
\text { (8) }\end{array}$ & $328 \pm 35^{d}$ & $124 \pm 18^{e, f}$ & $251 \pm 27^{d}$ & $88 \pm 16^{e .1}$ \\
\hline $\begin{array}{l}\text { Capsaicin + } \\
\text { guanethi- } \\
\text { dine (4) } \\
\end{array}$ & $116 \pm 24^{e}$ & $80 \pm 6^{e}$ & $87 \pm 7^{e}$ & $51 \pm 10^{e}$ \\
\hline $\begin{array}{l}{ }^{a} \text { Values are } \\
{ }^{b} \text { The numb } \\
\text { were used. } \\
{ }^{c} p \leq 0.05 \mathrm{vs} \\
{ }^{d} p \leq 0.01 \mathrm{v} \\
{ }^{e} p \leq 0.01 \mathrm{vs} \\
{ }^{c} p \leq 0.05 \mathrm{vs}\end{array}$ & $\begin{array}{l}\text { of nean } \pm \text { SEM } \\
\text { of is } 8 \\
\text { control. } \\
\text { combined tre } \\
\text { ontrol. } \\
\text { ombined tre }\end{array}$ & tment group. & heses; 5-mor & h-old animals \\
\hline
\end{tabular}

In a separate group of animals, the effect of capsaicin treatment upon retrograde transport of ${ }^{125} \mathrm{I}-\mathrm{NGF}$ was tested (Table VI). Accumulation of the material was depressed about $20 \%$ in the capsaicin-treated animals.

Superior cervical ganglion. As has been found many times before, guanethidine treatment reduced the ganglion to a small remnant, only $20 \%$ of control by dry weight (Table VII). Tyrosine hydroxylase activity, used in many laboratories as an indicator for surviving sympathetic neurons, was, as expected, reduced $96 \%$ to $98 \%$ in the ganglia from both groups of animals treated with guanethidine. The other four enzyme activities measured were reduced $85 \%$ to $95 \%$. None of the enzyme activities measured in this ganglion were affected by capsaicin treatment.

\section{Discussion}

Neonatal exposure to capsaicin produced an impressive decrease of 40 to $60 \%$ in the accumulation of FSAP activity both proximal and distal to the tie. Furthermore,

TABLE V

Fluoride-sensitive acid phosphatase activities and dry weight in pooled lumbar dorsal rool ganglia ( $L_{3}$ to $\left.L_{5}\right)$

\begin{tabular}{lccc}
\hline & TSAP & TRAP & $\begin{array}{c}\text { Dry } \\
\text { Weight }\end{array}$ \\
\hline & \multicolumn{2}{c}{$m m o l / k g / h r$} & $m g / 6$ ganglia \\
Control (5) $^{a}$ & $403 \pm 11$ & $427 \pm 12$ & $1.59 \pm 0.02$ \\
Capsaicin (5) $^{2}$ & $350 \pm 15^{b}$ & $199 \pm 14^{c}$ & $1.72 \pm 0.09$ \\
\hline
\end{tabular}

" The number of animals is given in parentheses; $2 \frac{1}{2}$-month-old animals were used.

${ }^{b} p \leq 0.05$ vs. control.

${ }^{c} p \leq 0.001$ vs. control.

TABLE VI

${ }^{125}$ I-NGF transport to dorsal root ganglia: Effect of capsaicin

${ }^{125}$ I-NGF in saline was injected subcutaneously in the left forepaw. Twelve hours later the dorsal root ganglia were removed and counted.

\begin{tabular}{lccc}
\hline & \multicolumn{3}{c}{ Cervical Dorsal Root Ganglia $\left(\mathrm{C}_{5}-\mathrm{C}_{8}\right)$} \\
\cline { 2 - 4 } & Left & Right & Difference \\
\hline & & $d p m / 4$ ganglia \\
Control (11) & $1768 \pm 113$ & $227 \pm 12$ & $1540 \pm 113$ \\
Capsaicin (10) $^{a}$ & $1454 \pm 83^{b}$ & $261 \pm 17$ & $1193 \pm 85^{b}$ \\
\hline
\end{tabular}

${ }^{a}$ The number of rats used is given in parentheses; 2-month-old animals were used.

${ }^{b} p \leq 0.05$ vs. control.

TABLE IV

Enzyme activities in dorsal root ganglia: Effects of capsaicin and guanethidine

\begin{tabular}{|c|c|c|c|c|c|c|}
\hline & $\mathbf{N}^{a}$ & FSAP & $\beta$-Glucuronidase & Glutaminase & Hexokinase & $\begin{array}{c}\text { Glutamic } \\
\text { Dehydrogenase }\end{array}$ \\
\hline & & & & $\mathrm{mmol} / \mathrm{kg} / \mathrm{hr}$ & & \\
\hline Control & 12 & $221 \pm 20$ & $9.4 \pm 0.8$ & $164 \pm 13$ & $1129 \pm 75$ & $1282 \pm 68$ \\
\hline Guanethidine & 13 & $254 \pm 16^{d}$ & $10.2 \pm 0.6^{d}$ & $178 \pm 10^{e}$ & $1367 \pm 58^{b, e}$ & $1382 \pm 77$ \\
\hline $\begin{array}{l}\text { Capsaicin + gua- } \\
\text { nethidine }\end{array}$ & 7 & $150 \pm 11^{\circ}$ & $6.9 \pm 0.7^{b}$ & $138 \pm 14$ & $1132 \pm 64$ & $1220 \pm 83$ \\
\hline
\end{tabular}

${ }^{a} \mathrm{~N}$ indicates the number of ganglia; 5-month-old animals were used.

${ }^{b} p \leq 0.05$ vs. control.

$c \leq 0.01$ vs. control.

${ }^{d} p \leq 0.01$ vs. combined treatment.

${ }^{e} p \leq 0.05$ vs. combined treatment. 
TABLE VII

Enzyme activities and dry weight of superior cervical ganglion: Effects of capsaicin and guanethidine

\begin{tabular}{|c|c|c|c|c|c|}
\hline & Dry Weight & $\begin{array}{c}\text { Tyrosine } \\
\text { Hydroxylase }\end{array}$ & $\mathrm{AChE}$ & Glutaminase & FSAP \\
\hline & $\mu$ g/ganglion & \multicolumn{4}{|c|}{ units/ganglion } \\
\hline Controls $(6)^{a}$ & $264 \pm 29$ & $2.82 \pm 0.24$ & $1280 \pm 70$ & $77 \pm 10$ & $116 \pm 14$ \\
\hline Capsaicin (4) & $244 \pm 20$ & $2.69 \pm 0.09$ & $1280 \pm 30$ & $62 \pm 3$ & $130 \pm 9$ \\
\hline Guanethidine (4) & $46 \pm 6$ & $0.04 \pm 0.02$ & $120 \pm 20$ & $6 \pm 0.5$ & $17 \pm 2$ \\
\hline $\begin{array}{l}\text { Capsaicin + guanethi- } \\
\text { dine (4) }\end{array}$ & $56 \pm 19$ & $0.11 \pm 0.06$ & $120 \pm 50$ & $5 \pm 2$ & $16 \pm 7$ \\
\hline
\end{tabular}

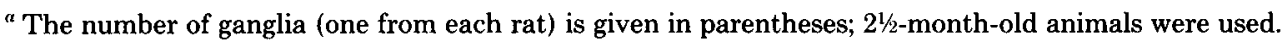

guanethidine treatment reduced the accumulation of FSAP activity 10 to $20 \%$, and combined treatment reduced FSAP accumulation about $70 \%$. This reduction is comparable to that seen in animals exposed to maternal anti-nerve growth factor (McDougal et al., 1981). Since the sympathectomy in the animals exposed to anti-NGF (Gorin and Johnson, 1979; Johnson et al., 1980) was almost as complete as that in the guanethidine-treated animals, the data suggest that most of the FSAP activity in transit in sensory axons is in the axons of capsaicinsensitive neurons. At the dose used $(50 \mathrm{mg} / \mathrm{kg})$, capsaicin appears to affect primarily small sensory neurons with unmyelinated axons (Jancsó et al., 1977; Scadding, 1980). Although the TRAP fraction of the transported FSAP activity was by far the larger and was the more severely affected by capsaicin treatment, accumulation of TSAP, the probable lysosomal activity, was reduced about $40 \%$ in the nerves of capsaicin-treated animals. Since the capsaicin-sensitive axons appear to constitute no more than 5 to $10 \%$ of the dry weight of the nerve, TSAP activity, and perhaps consequently lysosomes, may be relatively concentrated in these small axons. The changes observed in the accumulation of $\beta$-glucuronidase activity, another lysosomal enzyme, were quite small, however, and were statistically significant in only one comparison. Therefore the question whether TSAP is a representative of lysosomal enzymes, generally, or has some special role in small sensory neurons must be left open.

Guanethidine treatment resulted in a decrease of about $1 / 3$ in the accumulation of AChE activity both proximal and distal to the tie, in keeping with findings reported earlier (Schmidt et al., 1978). In contrast, neonatal exposure to capsaicin did not affect the accumulation of AChE activity. In only one comparison was a small, statistically significant change observed. The four comparisons together suggest no change. In three earlier experiments capsaicin produced no decrease at all in the accumulation of $\mathrm{AChE}$ activity proximal or distal to the tie, although in these same experiments accumulation of FSAP activity was depressed an average of $58 \%$ (not shown).

Both treatments resulted in a drop in the proximal and distal accumulations of the mitochondrial enzyme activities. In the animals exposed to both capsaicin and guanethidine, the effects were approximately additive. The changes were most clearly seen with glutaminase activity, perhaps because the accumulation of this activity, relative to the intrinsic activity in the nerve (Fig. 1), was much greater than for the other two enzymes. The results suggest that unmyelinated axons transport relatively large amounts of mitochondrial enzymes and hence large numbers of mitochondria. Since these axons have a very large surface-to-volume ratio and, presumably, a correspondingly high energy requirement, it seems plausible that the provision of relatively large numbers of mitochondria is a response to this requirement. These data suggest that all three mitochondrial enzymes measured respond similarly to the two treatments and provide no evidence in support of the earlier suggestion that hexokinase and glutamic dehydrogenase are affected differentially by guanethidine (Schmidt et al., 1978).

In the dorsal root ganglia of capsaicin-treated animals, the activities of FSAP and $\beta$-glucuronidase were both reduced about $30 \%$. Glutaminase activity was reduced about $25 \%$. The activities of the other two mitochondrial enzymes measured were unchanged. The same enzymes were affected, and to the same extent, in the dorsal root ganglia of the animals exposed to prenatal maternal antiNGF (McDougal et al., 1981). The decrease in transport of ${ }^{125}$ I-NGF to the dorsal root ganglia, however, was much less in capsaicin-treated animals (20\%) than in rats exposed to prenatal anti-NGF (75\%; Gorin and Johnson, 1979), suggesting that the ganglia exposed to anti-NGF lost many more neurons than did those exposed to capsaicin. This suggestion is supported by the fact that the decrease in ganglionic dry weight produced by capsaicin, if any, was small and inconsistent, while exposure to prenatal anti-NGF produced a substantial decrease in dry weight (40\%; McDougal et al., 1981) and protein (26\%; Gorin and Johnson, 1979) in the sensory ganglia. Exposure to prenatal anti-NGF resulted in a $70 \%$ decrease in the number of neurons in dorsal root ganglia (Johnson et al., 1980). Cell counts in dorsal root ganglia after neonatal capsaicin (reatment do not appear to have been done, but Jancsó et al. (1978) found what they interpreted to be histochemical evidence of cell damage in an estimated $30 \%$ of the neurons in the Gasserian ganglion 30 min after neonatal capsaicin treatment. Even if all of these were destined to die, the loss of neurons would be less than half of that in the ganglia exposed to anti-NGF. Whether the proportion of capsaicin-sensitive neurons in Gasserian ganglion is the same as that in dorsal root ganglia is unknown.

Furthermore, the results of these experiments indicate that it is the capsaicin-sensitive neurons that are particularly rich in FSAP, $\beta$-glucuronidase, and glutaminase activities and that depletion of these neurons from the sensory ganglia both by capsaicin and by exposure to anti-NGF accounts for the decreases in ganglionic enzyme activities. The concentrations of these same enzyme activities in the anti-NGF-sensitive, capsaicin-insensitive neuronal perikarya may be no higher than those 
in the other cellular elements in the ganglia. In keeping with its effects on the transported activities, the effect of capsaicin in dorsal root ganglia was greater upon the tartrate-resistant than upon the tartrate-sensitive acid phosphatase activity. The reduction in TRAP activity was more than $50 \%$, greater than for any of the other enzyme activities measured. Although the results of slide histochemistry imply an even greater reduction than this, the difficulties in drawing quantitative conclusions from what are, admittedly, essentially qualitative data are so great that the discrepancy may be only apparent. Since the function of this enzyme activity is quite unknown, it would be futile to speculate on the reason for its presence in these neurons. It is of interest that the small neurons in dorsal root ganglia may contain substance $\mathrm{P}$ or somatostatin (Hökfelt et al., 1976) or acid phosphatase. Although no two of these substances appear to dwell in the same neuron (Nagy and Hunt, 1982), all are depressed by capsaicin treatment.

Although the enzyme activities depressed in the two types of ganglion by their respective chemotoxins also were depressed in transit in sciatic nerve, it is not yet known whether the amount of enzyme exported via axonal transport is a direct function of its concentration in the perikaryon or whether perikaryal and transported enzyme activities are regulated independently.

The evidence from the present experiments suggests that capsaicin has no effect upon sympathetic neurons, nor, since most of the AChE in motion in peripheral nerve is probably in motor axons and since capsaicin produces no effect upon the $\mathrm{AChE}$ in transit in the nerve, does there appear to be an effect upon somatic motor neurons. Similarly, guanethidine treatment does not appear to produce any effect upon dorsal root ganglia.

It appears likely that the terminals of peripheral nerves are repeatedly lost and replaced (Cotman et al., 1981). It may be, as Barker and Ip (1965) have suggested for motor nerve endings, that nerve terminals have a fixed life span, requiring repeated replacement. But it also seems likely that some nerve endings are exposed to repeated trauma, so that replacement is necessary to prevent traumatic denervation. Probably, both factors play a part, but the role of trauma is likely to be greater in neurons innervating superficial tissues, particularly in those neurons whose function is to signal potential or actual damage to the organism. This latter category would include the neurons damaged irreparably by neonatal capsaicin at the dose used in this study. As pointed out by TownesAnderson and Raviola (1978), lysosomal participation would be expected in the dissolution of nerve endings, and they present evidence for acid phosphatase-containing bodies in what they interpret to be degenerating axons in normal ciliary body.

Nothing is known as yet of the rate of nerve terminal turnover in normal animals. If there is a basal rate, dependent upon a fixed life span as suggested by Barker and Ip (1965), one would expect the rate to be increased by trauma incidental to the normal functioning of the terminals. The relatively large amounts of lysosomal acid phosphatase activity in transit in the small band of sensory neurons whose nociceptive terminals are distributed to the surfaces of the organism may have evolved in response to the organism's need to replace these termi- nals quickly and repeatedly to prevent potentially lethal peripheral anesthesia.

There is evidence in the literature suggesting that lysosomes may, in some cells, play a role in membrane retrieval (Ottosen et al., 1980). If this is true of neurons, the fact that the lysosomal acid phosphatase is highly concentrated in capsaicin-sensitive sensory neurons suggests that this membrane retrieval system would be more active in these neurons than in motor neurons or in sensory neurons with large, myelinated axons.

\section{References}

Barker, D., and M. C. Ip (1965) Sprouting and degeneration of mammalian motor axons in normal and de-afferentated skeletal muscle. Proc. R. Soc. Lond. (Biol.) 163: 538-554.

Chaimovich, H., and F. Nome (1970) Purification and properties of an acid phosphatase from bovine brain. Arch. Biochem. Biophys. 139: 9-16.

Cotman, C. W., M. Nieto-Sampedro, and E. W. Harris (1981) Synapse replacement in the nervous system of adult vertebrates. Physiol. Rev. 61: 684-784.

Csillik, B., and E. Knyihár (1978) Biodynamic plasticity in the Rolando substance. Prog. Neurobiol. 10: 203-230.

Gerebtzoff, M. A., and T. Maeda (1968) Caractères et localization histochemique d'un isoenzyme fluororésistant de la phosphatase acide dans la moelle epiniére du rat. C. R. Soc. Biol. (Paris) 162: 2032-2035.

Gorin, P. D., and E. M. Johnson, Jr. (1979) Experimental autoimmune model of nerve growth factor deprivation: Effects on developing peripheral sympathetic and sensory neurons. Proc. Natl. Acad. Sci. U. S. A. 76: 5382-5386.

Hökfelt, T., R. Elde, O. Johansson, R. Luft, G. Nilsson, and A. Arimura (1976) Immunohistochemical evidence for separate populations of somatostatin-containing and substance $\mathrm{P}$-containing primary afferent neurons in the rat. Neuroscience 1: 131-136.

Jancsó, G., and E. Knyihár (1975) Functional linkage between nociception and fluoride-resistant acid phosphatase activity in the Rolando substance. Neurobiology 5: 42-43.

Jancsó, G., E. Kiraly, and A. Jancsó-Gábor (1977) Pharmacologically induced selective degeneration of chemosensitive primary sensory neurons. Nature 270: 741-743.

Jancsó, G., G. Sávay, and E. Kiraly (1978) Appearance of histochemically detectable ionic calcium in degenerating primary sensory neurons. Acta Histochem. 62: 165-169.

Jessell, T. M., L. L. Iversen, and A. C. Cuello (1978) Capsaicininduced depletion of substance $P$ from primary sensory neurons. Brain Res. 152: 183-188.

Johnson, E. M., Jr., E. Cantor, and J. R. Douglas, Jr. (1975) Biochemical and functional evaluation of the sympathectomy produced by the administration of guanethidine to newborn rats. J. Pharmacol. Exp. Ther. 193: 503-512.

Johnson, E. M., Jr., P. D. Gorin, L. D. Brandeis, and J. Pearson (1980) Dorsal root ganglion neurons are destroyed by exposure in utero to maternal antibody to nerve growth factor. Science 210: 916-918.

Johnson, E. M., F. O'Brien, and R. Werbitt (1976) Modification and characterization of the permanent sympathectomy produced by the administration of guanethidine to newborn rats. Eur. J. Pharmacol. 37: 45-54.

Knyihár, E., and M. A. Gerebtzoff (1973) Extralysosomal localization of acid phosphatase in the spinal cord of the rat. Exp. Brain Res. 18: 383-395.

McDougal, D. B., Jr., M. J. C. Yu, P. D. Gorin, and E. M. Johnson, Jr. (1981) Transported enzymes in sciatic nerve and sensory ganglia of rats exposed to maternal antibodies against nerve growth factor. J. Neurochem. 36: 1847-1852.

Nagatsu, T., M. Levitt, and S. Udenfriend (1964) Tyrosine 
hydroxylase: The initial step in norepinephrine biosynthesis. J. Biol. Chem. 239: 2910-2917.

Nagy, J. I., and S. P. Hunt (1982) Fluoride-resistant acid phosphatase containing neurons in dorsal root ganglia are separate from those containing substance P or somatostatin. Neuroscience 7: 89-97.

Ottosen, P. D., P. J. Courtoy, and M. G. Farquhar (1980) Pathways followed by membrane recovered from the surface of plasma cells and myeloma cells. J. Exp. Med. 152: 1-19.

Patel, A. J., A. Hunt, C. S. M. Tahourdin, R. D. Gordon, and S. Bunn (1981) Metabolic compartmentation of glutamate: Cellular localization of certain relevant enzymes and the induction of glutamine synthetase in the brain in vivo. Soc. Neurosci. Abstr. 7: 935.

Reiner, J. M., K. K. Tsuboi, and P. B. Hudson (1955) Acid phosphatase. IV. Fluoride inhibition of prostatic acid phosphatase. Arch. Biochem. Biophys. 56: 165-183.

Robins, E., H. E. Hirsch, and S. S. Emmons (1968) Glycosidases in the nervous system. I. Assay, some properties, and distri- bution of $\beta$-galactosidase, $\beta$-glucuronidase and $\beta$-glucosidase. J. Biol. Chem. 243: 4246-4252.

Scadding, J. W. (1980) The permanent anatomical effects of neonatal capsaicin on somatosensory nerves. J. Anat. 131: 473-484.

Schmidt, R. E., and D. B. McDougal, Jr. (1978) Axonal transport of selected particle-specific enzymes in rat sciatic nerve in vivo and its response to injury. J. Neurochem. 30: 527-535.

Schmidt, R. E., C. D. Ross, and D. B. McDougal, Jr. (1978) Effects of sympathectomy on axoplasmic transport of selected enzymes including MAO and other mitochondrial enzymes. J. Neurochem. 30: 537-541.

Schmidt, R. E., M. J. C. Yu, and D. B. McDougal, Jr. (1980) Turnaround of axoplasmic transport of selected particle-specific enzymes at an injury in control and diisopropylphosphorofluoridate-treated rats. J. Neurochem. 35: 641-652.

Townes-Anderson, E., and G. Raviola (1978) Degeneration and regeneration of autonomic nerve endings in the anterior part of rhesus monkey ciliary muscle. J. Neurocytol. 7: 583-600. 